\title{
Evaluation of job stress models for predicting health at work
}

\author{
Cathrine Reineholm, Maria Gustavsson and Kerstin Ekberg
}

\section{Linköping University Post Print}

N.B.: When citing this work, cite the original article.

Original Publication:

Cathrine Reineholm, Maria Gustavsson and Kerstin Ekberg, Evaluation of job stress models for predicting health at work, 2011, WORK: A Journal of Prevention, Assessment and Rehabilitation, (40), 2, 229-237.

http://dx.doi.org/10.3233/WOR-2011-1223

Copyright: IOS Press

http://www.iospress.nl/

Postprint available at: Linköping University Electronic Press

http://urn.kb.se/resolve?urn=urn:nbn:se:liu:diva-57254 
Running head: Job stress models for predicting health at work

\section{Evaluation of job stress models for predicting health at work}

CATHRINE REINEHOLM ${ }^{\mathrm{a}, \mathrm{b}}$, MARIA GUSTAVSSON ${ }^{\mathrm{a}, \mathrm{c}}$, \& KERSTIN $\mathrm{EKBERG}^{\mathrm{a}, \mathrm{b}}$

${ }^{a}$ HELIX VINN Excellence Centre, Linköping University, 58183 Linköping, Sweden

${ }^{b}$ National Centre for Work and Rehabilitation, Department of Medical and Health Sciences,

Linköping University, 58183 Linköping, Sweden

${ }^{c}$ Learning in Working Life and Educational Settings, Department of Behavioural Sciences and Learning, Linköping University, 58183 Linköping, Sweden

Correspondence: Cathrine Reineholm, HELIX VINN Excellence Centre, Linköping

University, 58183 Linköping, Sweden. Tel: +46 132844 06. Fax: +46 132251 00. E-mail:

cathrine.reineholm@liu.se 


\section{Evaluation of job stress models for predicting health at work}

\section{Abstract}

Objectives: Few workplace health promotion (WHP) interventions are designed to improve work conditions. Methods for measurement of work conditions are often developed from a risk factor perspective rather than a WHP perspective. More knowledge is needed on the work conditions that promote health in order to develop a good work environment. The purpose of the present study was to investigate if the Demand Control Support model, the Effort Reward Imbalance model and the Job Characteristic Inventory are correlated, if the subscales predict health and to analyze which combination of subscales is the most useful predictor of health longitudinally.

Participants: The study used questionnaire data from 662 civil servants at baseline and at follow-up 2 years later.

Method: The data were analysed by multiple regressions.

Results: A new model; effort, reward, and variety, was found having a higher predictive power to predict health than the original models.

Conclusions: To promote health at work, social relations and health-mediating work conditions are important because these conditions may buffer health. Health can be assumed to be a resource that is created in everyday activities and interactions in workplaces, and there is a need to develop health measure instruments based on holistic health theories.

Keywords: Work conditions, job stress models, health, workplace health promotion 


\section{Introduction}

Studies of occupational health often focus on risk factors defined as symptoms and signs of disorders such as stress and burnout rather than on the conditions that promote health [20]. Determinants of ill-health are better known than determinants of good health, partly because of the difficulties in defining and measuring good health. Mackenbach, van den Bos, Joung, van de Mheen, and Stronks [11] have found that determinants of good health and ill-health have similar, but mirrored patterns. This means that reduction of risk factors for ill-health can be assumed to have much in common with factors related to good health, but these relations need further elaboration. Prevention refers to identify and minimize risk factors for ill-health. Health promotion, on the other hand, is focusing on strategies to increase employees' health and wellbeing. To promote good health at work, more knowledge on the work conditions that promote health is needed in order to develop a good work environment.

Few studies on workplace health promotion (WHP) are designed to improve work conditions and the work environment is often overlooked $[6,12]$. WHP may have various foci (e.g. individual behaviours, work tasks, communication, organizational development). WHP strategies are often worker-directed and focus on health-related attitudes and individual

lifestyle behaviours $[1,16]$. Therefore different practices need different types of evaluation of health.

Health can be seen from different perspectives. The bio-medical approach to health has its starting point in disease or illness and sees health as the absence from disease, e.g. Boorse [4], while other theorists such as Pörn [19] and Nordenfelt [17] representing the holistic perspective, do not rely on the concept of disease and has a action-theoretical approach to health where health is related to a person's action ability. 
Health promotion is often described as a process of enabling people to take action, to exert control over the determinants of health [18]. Health promotion may correspond to a holistic approach to health where health is seen as a person ability to act, given the standard circumstances in his environment to fulfill his goals [17] or when a person's repertoire is adequate relative to his profile of goals [19].

As the concept of health is complex, health is difficult to measure with standardized instruments [8]. Most health measurement instruments measure health in negative outcomes, e.g. mortality, morbidity or symptoms, that is, a biomedical approach to health. Even if subjective, self-rated health instruments, such as the Short Form (36) Health Survey (SF-36) [24] and the European Quality of Life 5 Dimensions (EQ-5D) [7], reflect a person's integrated perception of health, there is a need for valid instruments to measure health from a holistic perspective that capture the subjective dimension as well as the individual's ability and resources. This may be done by development of new instruments but as instrumental development requires considerable effort, it seems reasonable to first evaluate the usefulness of the instruments that are commonly used today.

Development of evidence-based WHP programs requires thorough analyses of instruments to measure work conditions and changes in work conditions after interventions. Most wellvalidated methods for measurement of work conditions are developed from a risk factor perspective rather than a WHP perspective. The Job Demand Control Support (DCS) model by Karasek and Theorell [9] and the Effort Reward Imbalance (ERI) model by Siegrist [22] have been the dominating models in research on associations between psychosocial work conditions and ill-health. The two models have been used in numerous studies, mainly with outcomes such as coronary heart disease (CHD), work-related stress or mental strain. The somewhat older Job Characteristic Inventory (JCI) by Sims, Szilagyi and Keller [23] aims to measure how work conditions relate to productivity and job satisfaction, and may therefore be 
interesting from an organizational perspective. It is based on six dimensions of work conditions: variety, autonomy, task identity, feedback, dealing with others and friendship opportunities. The JCI model is not as commonly used as the DCS model and the ERI model, but according to Wall, Jackson, Mullarkey and Parker [26], the JCI model presents an overall measure of job complexity that includes opportunities to learn new things, develop and exercise a high level of skill, use one's ability and creativity, and experience variety. These aspects may be relevant in modern working life and for WHP. Thus, the DCS model and the ERI model are well validated models for predicting ill-health, while the purpose with the JCI model is to predict job satisfaction but it is unclear how these models predict health.

The aim of the present study is to investigate if the subscales in the DCS model, the ERI model and the JCI model are correlated, if the subscales predict health and to analyze which combination of subscales is the most useful predictor of health longitudinally.

\section{Methods}

\section{Materials}

A mailed questionnaire was sent to all employees (including those on the sick list and on leave of absence, $N=1010$ ) at three regional organizations of the National Labour Market Administration (AMV). Of the 1010 employees, 602 (60\%) were woman and 408 (40\%) were men. The average age was 48.7 years, ranging from 25 to 65 years, and most of the respondents were working as employment officers in local employment agencies. In all, 792 subjects $(78 \%)$ responded to the questionnaire. Near half of the respondents $(45 \%)$ had a university degree and $43 \%$ had a degree from upper secondary school.

A follow-up questionnaire was sent 2 years after the first questionnaire to those who had responded to the first questionnaire. The follow-up questionnaire was answered by 662 
respondents (66\%). Respondents who had retired between baseline and the follow-up $(n=15)$ were excluded from the subsequent analysis.

The study was approved by the university's Ethics Committee.

\section{Measures}

Demographic variables. Sex, age and education level were used as demographic variables.

Work conditions. The variables used to measure work conditions were demands, control, social support from the DCS model [9], effort, reward from the ERI model [22], and variety, feedback, autonomy and task identity from the JCI model [23]. All the response scales were 4or 5-point Likert scales.

Health. Measures of health were chosen to capture the full range of good health to illhealth. The three health measures in this study are assumed to capture different aspects of health, from good health by measuring subjective well-being and energy (the vitality scale) to ill-health by measuring exhaustion and burnout, while the VAS scale covers the full range from best imaginable health state to worst imaginable health state. All three measures are well validated and have good psychometric properties [7, 10, 24]. The SF-36 [24, 27] and the EQ5D [7] are generic instruments and designed to be applicable to a wide range of physical and mental health conditions.

SF-36 is a multi-purpose, short-form health survey with 36 questions, attempts to represent a multi-dimensional health concept and measure the full range of health status, including well-being and personal evaluations of health. Vitality, as a component of good health, was measured by the vitality scale from the SF-36. The vitality scale captures health states ranging between feeling tired and worn out to feeling full of pep and energy. One example item for 
measuring vitality is: "How much of the time during the 4 past weeks did you have a lot of energy?" The response scale is an 8-point Likert scale (1, all of the time; 8 , none of the time).

The EQ-5D is a non-disease-specific instrument that aims to cover the full health spectrum from best to worst. Health-related quality of life was measured by the Visual Analogue Scale (VAS) from the EQ-5D instrument. The purpose of the self-rating scale VAS scale is to capture overall health; the respondents rate their current physical and mental health state ranging from 0 ("the worst state you can imagine") to 100 ("the best state you can imagine").

Burnout. The Copenhagen Burnout Inventory (CBI) was developed to measure ill-health, burnout, anxiety and fatigue [10]. Only the generic part of the CBI, personal burnout, was used in the present study as an indicator of general burnout because it can be answered by everyone, regardless of occupational status (employed, unemployed, retired, etc.). The scale is intended to answer the question "How tired or exhausted are you?" and the response scale is a 5-point Likert scale (1, always; 5, never/almost never). The scale ranges from 0 to 100; the first category (always) is scored 100 and the fifth category (never/almost never) is scored 0 .

\section{Statistical analysis}

The relationship between the variables was examined using Pearson correlation analysis. The distribution of means and standard deviations of self-rated health and burnout at baseline and at follow-up, in relation to the demographical variables sex, age and education, were calculated using the $t$-test and ANOVA. Significant differences were further examined by the Bonferroni post-hoc test.

The power of the three models (the DCS model, the ERI model and the JCI model) to predict health longitudinally was compared by stepwise multiple linear regression analyses for each model (probability of $F$, entry 0.05 and removal 0.10 ). Working conditions and 
demographic variables at baseline were independent variables and the two health measures and burnout at the 2-year follow-up were dependent variables throughout all analyses.

The relationship between the work condition variables from the three models and health was investigated with simple linear regressions.

Multiple stepwise regressions were performed (probability of $F$, entry 0.05 and removal 0.10) to investigate associations between work conditions and health and ill-health longitudinally. The three variables with the highest explained variance in the simple linear regressions and demographic variables at baseline were independent variables, and the two health measures and burnout at the 2-year follow-up were dependent variables.

Internal consistency. Cronbach's alpha $(\alpha)$ is a measure of internal consistency, that is, how well the items of a scale measure a single unidimensional latent construct. According to Bland and Altman [3] the recommended value of Cronbach's $\alpha$ should exceed .70 to be acceptable, but in non-clinical studies the $\alpha$ value can be lower $[5,13]$ and the $\alpha$ value is satisfactory if it exceeds .60. The control scale was slightly below this value $(\alpha=.54)$. The demands scale $(\alpha=.69)$ and the autonomy scale $(\alpha=.69)$ were close to .70 and the remaining scales (social support, effort, reward, variety, feedback, task identity) were $>.70$. If one scale is slightly below the recommended value, and the other scales are above, the internal consistency can be seen as satisfactory [5].

SPSS version 15.0 was used for the statistical analyses. 


\section{Results}

Non-response

The response rate was $66 \%$. Non-response and dropouts were analysed with regard to sex, age and regional organization and no significant differences were found. The responders were older than the non-responders at baseline $(p<.01)$ and at the follow-up $(p<.01)$.

\section{Demographics}

Descriptive statistics (means and standard deviations) of self-rated health and burnout according to sex, age and education are presented in Table 1. Women rated their health as poorer than men in all three outcome measures both at baseline VAS $t(742)=2,11, p<.05$, vitality $t(764)=5,13, p<.001$, burnout $t(767)=-4,44, p<.001$ and at the follow-up VAS $t(663)=2,38, \mathrm{p}<.05$, vitality $t(595)=4,58, p<.001$, burnout $t(594)=-4,23, p<.001$. Burnout at follow-up differed between age groups $F(3,592)=2,97, p<.05$, respondents aged 35-44 years had the highest burnout score. The educational groups did not differ in the outcome measures.

\section{[Insert Table 1 about here]}

\section{Work conditions}

Correlations between all variables in the three models for measuring work conditions are presented in Table 2. In general, correlations were low, but significant. Three groups of related variables emerged. Demands in the DCS model had a high correlation with effort in the ERI model $(r=.69, p<.001)$. Social support in the DCS model had high correlation with reward in the ERI model $(r=.55, p<.001)$ and with feedback in the JCI model $(r=.34, p<.001)$. Control in the DCS model had high correlation with variety $(r=.62, p<.001)$ and with autonomy $(r=.45, p<.001)$ in the JCI model. 


\section{Health measures}

High correlations were obtained between the three health measures. At baseline, VAS and vitality had a positive correlation $(r=.68, p<.001)$, and the burnout measure CBI had high negative correlations with VAS $(r=-.56, p<.001)$ and with vitality $(r=-.74, p<.001)$. Negative signs are due to scale constructions. The correlations were slightly higher at the follow-up. When comparing the stability in ratings, that is, the correlation between baseline and the follow-up, a higher correlation was found between baseline and follow-up for burnout $(r=.71$, $p<.001)$ than for VAS $(r=.57, p<.001)$ and vitality $(r=.59, p<.001)$.

[Insert Table 2 about here]

\section{Longitudinal associations with health}

The power of the three original models (the DCS model, the ERI model and the JCI model) to establish longitudinal associations between work conditions and health outcomes was compared in terms of explained variance in the regression models. Results are presented model by model in Table 3 .

The DCS model and the ERI model had higher predictive power than the JCI model for all three health outcomes. All three models had a higher explained variance $\left(R^{2}\right)$ for the outcome measure burnout than for the other two health measures. For the JCI model, there was only a small difference between the explained variance for burnout $\left(R^{2}=.129\right)$ and vitality $\left(R^{2}=.114\right)$. The VAS scale had the lowest explained variance in all three models.

[Insert Table 3 about here] 
The univariate linear regression analysis of the relationship between work conditions and health 2 years later is presented in Table 4. Reward, variety and social support had the highest score regarding association with health as measured by the VAS scale. Demands, effort and reward had the highest score regarding association with health measured by the vitality scale and with burnout.

[Insert Table 4 about here]

Based on the results of the univariate linear regression analysis, the three work condition variables with the highest score for each health measure instrument were used as predictors in a multiple stepwise regression analysis (Table 5). Reward, variety and effort were best predictors of health longitudinally, measured by the VAS scale and the vitality scale. Effort, reward, variety and demands were best predictors of ill-health longitudinally, measured by burnout. Reward, variety and effort had a moderate explained variance for the VAS scale $\left(R^{2}=.104\right)$; the explained variance for vitality was higher $\left(R^{2}=.174\right)$. The highest explained variance was obtained for effort, reward, variety and demands, predicting burnout $\left(R^{2}=.265\right)$.

[Insert Table 5 about here]

\section{Discussion}

The purpose of this study was to investigate if the subscales in the DCS model, the ERI model and the JCI model were correlated, if the subscales predicted health and to analyze which combination of subscales was the most useful predictor of health longitudinally.

The results show that all three original job stress models are better predictors of ill-health (in this study burnout) than of health. One explanation could be that the models were developed to identify risk factors associated with ill-health, from a preventive perspective [2]. 
Within WHP, the focus is on measurement of work conditions that promote health development.

Three groups of work conditions emerged with high inter correlations between variables from the three original job stress models. Demands and effort may be assumed to be determined by organizational conditions, which the employees' may have minor possibilities to influence. The second group, social support and reward, capture social relations such as communication and interactions and may provide opportunities to cope with organizational work conditions such as effort and demands [25]. The third group, control, variety and autonomy, measure decision-making, planning and involvement; that is, they capture the ability to influence or decide on the work situation and motivation [14].

If organizational work conditions, such as effort and demands, determine the employees' degrees of freedom, work conditions supporting social relations (reward and social support) may improve the ability to act, in order to change the work situation. The third group, variety, autonomy and control, is interpreted as health-mediating work conditions. These conditions may enrich the job [14] and function as social resources that indirectly promote the employees' health. Thus, from a WHP perspective, health-mediating work conditions need to be considered to promote health at work.

Semmer [21] suggested that a combination of person-focused and organization-focused approaches is the most promising intervention. This means that the workplace as a context and the individuals need to be considered in workplace health promotion. Health promotion is often described as an activity to enable people to take action, to act individually or collectively to exert control over the determinants of health [18]. This means that health may be created in the social relations between employees at the workplace. It can also be assumed that employees with good health contribute to good health through their interactions with 
others. This highlights the importance of measuring work conditions that capture social relations among employees in workplaces.

The regression analysis confirmed the assumption that variables from the different original job stress models may be more useful in predicting health than the full original models. In this longitudinal study, a new model consisting of the work conditions variables effort, reward and variety, was found to have a higher predictive power of health than the original models. The work conditions in the new model are also represented by the three groups of work conditions: organizational work conditions, social relations and health-mediating work conditions. Thus, it is not only the balance between effort and reward that is of importance for employees' health but also the variety of work tasks. To promote health at work, an additional dimension needs to be added and the health-mediating work conditions (variety, autonomy and control) may capture that dimension.

On a scale or a continuum with health at the positive end and ill-health at the negative end, the different work condition variables are inclined towards different directions; that is, work conditions can be assumed to have similar but mirrored patterns, as suggested by Mackenbach et al. [11]. Effort and demands have a negative relationship with health and a positive relationship with ill-health. Reward and variety have a positive relationship with health but a negative relationship with ill-health. Thus, there are work condition variables, in this study reward and variety, that may predict health longitudinally.

Because most of the respondents worked in similar occupations in the same organization, they are a fairly homogeneous and healthy population. The associations between work conditions and health outcomes are therefore probably inflated, compared with populations with more varied work conditions. Despite this, this study shows that variables in traditional job stress models capture important aspects of health-promoting work conditions. 


\section{Conclusion}

Depending on the purpose, prevention or promotion, measurement of different work conditions is useful. Traditional job stress models capture important aspects of healthpromoting work conditions, but are better predictors for ill-health. To promote health at work, social relations and health-mediating work conditions are of importance because these conditions may buffer health. Thus, health can be assumed to be a resource that is created in everyday activities and interactions in workplaces, and therefore there is a need to develop health measure instruments based on holistic health theories.

\section{References}

1. H. Arneson and K. Ekberg, Evaluation of empowerment processes in a workplace health promotion intervention based on learning in Sweden, Health Promotion International 20 (2005), 351-359.

2. G. Aronsson and T. Lindh, Långtidsfriskas arbetsvillkor. En populationsstudie (Work conditions among workers with good long term health. A population study) (in Swedish), National Institute of Working Life, Stockholm, 2004.

3. J.M. Bland and D.G. Altman, Cronbach's alpha, BMJ 314 (1997), 572.

4. C. Boorse, Health as a theoretical concept. Philosophy of Science, 44 (1975), 542-573.

5. H. Bosma, M.G. Marmot, H. Hemingway, A.C. Nicholson, E. Brunner and S.A. Stansfeld, Low job control and risk of coronary heart disease in Whitehall II (prospective cohort) study, BMJ, 314 (1997), 558-565.

6. R. Bourbonnais, C. Brisson, A. Vinet, M. Vézina, B. Abdous and M. Gaudet, Effectiveness of a participative intervention on psychosocial work factors to prevent 
mental health problems in a hospital setting, Occupational Environmental Medicine, 63 (2006), 335-342.

7. R. Brooks and The EuroQol Group, EuroQol: The current state of play. Health Policy, 37 (1996), 53-72.

8. B. Brülde and P-A. Tengland, Hälsa och sjukdom - en begreppslig utredning (Health and disease - a conceptual analysis) (in Swedish), Studentlitteratur, Lund, Sweden, 2003

9. R. Karasek and T. Theorell, Healthy work: stress, productivity and the reconstruction of working life, Basic Books, New York, 1990.

10. T.S. Kristensen, M. Borritz, E. Villadsen and K.B. Christensen, The Copenhagen Burnout Inventory: a new tool for the assessment of burnout, Work \& Stress, 19 (2005), 192-207.

11. J.P. Mackenbach, J. van den Bos, I.M.A Joung, H. van de Mheen and K. Stronks, The determinants of excellent health: different from the determinants of ill-health? International Journal of Epidemiology, 23 (1994), 1273-1281.

12. S. Maes, C. Verhoeven, F. Kittel and H. Scholten, Effects of a Dutch work-site wellness-health program: The Brabantia Project, American Journal of Public Health, 88 (1998), 1037-1041.

13. R. McKinley, T. Manku-Scott, A.M. Hastings, D.P. French and R. Baker, Reliability and validity of a new measure of patient satisfaction with out of hours primary medical care in the United Kingdom: development of a patient questionnaire, $B M J$, 314 (1997), 193-202. 
14. F.P. Morgeson and S.E. Humphrey, The work design questionnaire (WDQ): developing and validating a comprehensive measure for assessing job design and the nature of work, Journal of Applied Psychology, 91 (2006), 1321-1339.

15. J. Naidoo and J. Wills, Health Promotion. Foundations for Practice, Second Edition, Baillière Tindall, New York; Edinburgh, 2000.

16. A. Noblet and A.D. LaMontagne, The role of workplace health promotion in addressing job stress, Health Promotion International, 21 (2006), 346-352.

17. L. Nordenfelt, On the nature of health. An action-theoretic approach, Kluwer Academic Publishers, Dordrecht, 1995.

18. D. Nutbeam, Evaluating health promotion - progress, problems and solutions, Health Promotion International, 13 (1998), 27-44.

19. I. Pörn, Health and adaptedness, Theoretical Medicine, 14 (1993), 295-303.

20. W. Schaufeli, The future of occupational health psychology, Applied Psychology, $\mathbf{5 3}$ (2004), 502-517.

21. N.K. Semmer, Job stress interventions and the organization of work, Scandinavian Journal of Environmental Health, 32 (2006), 515-527.

22. J. Siegrist, Adverse health effects of high effort/low reward conditions, Journal of Occupational Health Psychology, 1(1996), 27-41.

23. H.P. Sims Jr, A.D. Szilagyi and R.T. Keller, The measurement of job characteristics, Academy of Management Journal, 19 (1976), 195-212. 
24. M. Sullivan, J. Karlsson and J.E. Ware, The Swedish SF-36 health survey - I. Evaluation of data quality, scaling assumptions, reliability and construct validity across general populations in Sweden, Social Science \& Medicine, 41 (1995), 13491358.

25. C. Vanroelen, K. Levecque and F. Louckx, Psychosocial work conditions and selfreported health in a representative sample of wage-earners: a test of the different hypotheses of the Demand-Control-Support-Model, International Archive of Occupational Environmental Health, 82 (2009), 329-342.

26. T.D. Wall, P.R. Jackson, S. Mullarkey and S.K. Parker, The Demands-Control Model of job strain: a more specific test, Journal of Occupational and Organizational Psychology, 69 (1996), 153-166.

27. J.E Ware and C.D. Sherbourne, The MOS 36-item Short-Form Health Survey (SF36). I. Conceptual framework and item selection, Medical Care, 30 (1992), 473-483. 
Table 1. Descriptive statistics for health and burnout (means, standard deviations) distributed among sex, age and education level and results of ANOVA at baseline and at the follow-up.

\begin{tabular}{|c|c|c|c|c|c|c|}
\hline & \multicolumn{2}{|l|}{ VAS-scale } & \multicolumn{2}{|l|}{ Vitality } & \multicolumn{2}{|l|}{ Burnout } \\
\hline & Baseline & Follow-up & Baseline & Follow-up & Baseline & Follow-up \\
\hline \multicolumn{7}{|l|}{ Descriptive statistics } \\
\hline \multicolumn{7}{|l|}{ Sex } \\
\hline Women & $72.3(19.8)$ & $72.7(19.3)$ & $55.8(23.4)$ & $57.6(24.4)$ & $46.6(19.0)$ & $44.2(20.6)$ \\
\hline Men & $75.2(17.1)$ & $76.1(15.3)$ & $64.3(21.4)$ & $66.3(19.9)$ & $40.5(18.7)$ & $37.1(19.6)$ \\
\hline \multicolumn{7}{|l|}{ Age } \\
\hline Under 35 years & $76.9(13.7)$ & $75.0(16.0)$ & $58.3(21.5)$ & $58.7(21.1)$ & $43.6(18.8)$ & $40.9(20.2)$ \\
\hline $35-44$ years & $73.7(18.8)$ & $74.0(16.6)$ & $57.6(22.7)$ & $57.9(24.0)$ & $43.3(18.9)$ & $45.4(19.8)$ \\
\hline $45-54$ years & $72.4(18.5)$ & $73.5(19.3)$ & $58.7(23.3)$ & $59.7(22.9)$ & $44.7(18.8)$ & $42.1(20.4)$ \\
\hline 55 years or older & $73.5(20.1)$ & $74.4(19.3)$ & $61.4(23.1)$. & $64.3(23.0)$ & $42.0(19.4)$ & $38.6(20.7)$ \\
\hline \multicolumn{7}{|l|}{ Education } \\
\hline Compulsory school & $70.3(21.3)$ & $69.4(20.0)$ & $60.1(22.7)$ & $59.2(23.6)$ & $43.2(18.6)$ & $42.9(22.9)$ \\
\hline 2 years upper secondary school & $74.3(18.3)$ & $75.3(17.6)$ & $62.0(23.0)$ & $62.1(22.5)$ & $43.7(20.0)$ & $40.3(19.1)$ \\
\hline 3-4 years upper secondary school & $73.8(18.4)$ & $74.1(18.4)$ & $59.4(21.6)$ & $62.6(23.2)$ & $43.7(18.6)$ & $41.2(21.2)$ \\
\hline University & $73.4(18.7)$ & $74.4(17.3)$ & $58.2(23.4)$ & $60.1(23.5)$ & $44.4(18.9)$ & $41.8(20.4)$ \\
\hline \multicolumn{7}{|l|}{ ANOVA } \\
\hline \multicolumn{7}{|l|}{ Sex } \\
\hline$t(\mathrm{df})$ & $2.11(742)$ & $2.38(663)$ & $5.13(764)$ & $4.48(595)$ & $-4.44(767)$ & $-4.24(594)$ \\
\hline $\mathrm{p}$ & .035 & .017 & $<.001$ & $<.001$ & $<.001$ & $<.001$ \\
\hline \multicolumn{7}{|l|}{ Age } \\
\hline$F\left(\mathrm{df}^{1}, \mathrm{df}^{2}\right)$ & $1.05(3,740)$ & $0.15(3,661)$ & $1.18(3,762)$ & $2.58(3,593)$ & $1.85(3,765)$ & $297(3,592)$ \\
\hline$p$ & .371 & .928 & .318 & .053 & .136 & .031 \\
\hline \multicolumn{7}{|l|}{ Education } \\
\hline$F\left(\mathrm{df}^{1}, \mathrm{df}^{2}\right)$ & $0.52(4,739)$ & $1.42(4,659)$ & $1.77(4,761)$ & $0.48(4,592)$ & $0.44(4,764)$ & $0.45(4,591)$ \\
\hline$p$ & .722 & .225 & .132 & .752 & .777 & .775 \\
\hline
\end{tabular}


Table 2. Bivariate correlations between the variables $(n=662)$.

$\begin{array}{llllll}1 . & 2 . & 3 . & 4 . & 5 .\end{array}$.

Work conditions

\section{Variety}

2. Autonomy $\quad .38 * * *$

3. Feedback $\quad .14 * * * \quad .23 * * *$

4. Task identity $\quad .23 * * * \quad .53 * * * \quad .29 * * *$

5. Demands $\quad \begin{array}{lllll}.05 & -.21 * * * & -.18 * * * & -.12 * *\end{array}$

$\begin{array}{llllll}\text { 6. Control } & .62 * * * & .45 * * * & .17 * * * & .24 * * * & -.04\end{array}$

$\begin{array}{llllll}\text { 7. Social support } \quad .12 * * \quad .20 * * * \quad .34 * * * \quad .14 * * * & -.34 * * * \quad .24 * * *\end{array}$

$\begin{array}{llllllll}\text { 8. Effort } & .06 & -.20 * * * & -.18^{* * *} & -.10^{* *} & .69^{* * *} & -.03 & -.33^{* * *}\end{array}$

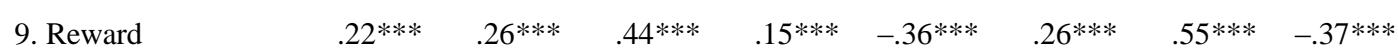

\section{Health}

10. VAS-scale time $1 \quad .14 * * * \quad .22 * * * \quad .20 * * * \quad .14 * * * \quad-.21 * * * \quad .17 * * * \quad .29 * * * \quad-.27 * * * \quad .34 * * *$

11. Vitality time $1 \quad .12 * * * \quad .21 * * * \quad .28 * * * \quad .17 * * * \quad-.27 * * * \quad .14 * * * \quad .31^{* * *} \quad-.36^{* * *} \quad .40^{* * *} \quad .68 * * *$

12. Burnout time $1 \quad-.15 * * * \quad-.24 * * * \quad-.28 * * * \quad-.19 * * * \quad .41 * * * \quad-.17 * * * \quad-.34 * * * \quad .50 * * * \quad-.45 * * * \quad-.56 * * * \quad-.74 * * *$

13. VAS-scale time $3 \quad .21^{* * *} \quad .12 * * \quad .13^{* * *} \quad .13^{* *} \quad-.16^{* * *} \quad .18^{* * *} \quad .21^{* * *} \quad-.16^{* * *} \quad .26^{* * *} \quad .57^{* * *} \quad .46^{* * *} \quad-.45^{* * *}$

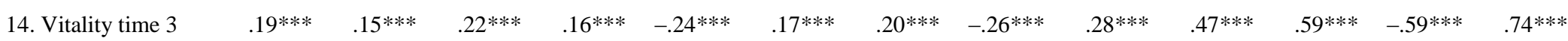

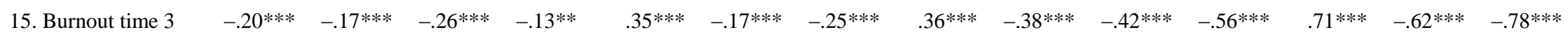

$* p<.05, * * p<.01, * * * p<.001$. 
Table 3. Multiple stepwise regression of self-rated health and burnout on each model at the follow-up $\left(R^{2}\right.$, unstandardized beta coefficient, standardized beta coefficient and $p$-value), controlled for sex, age and education.

\begin{tabular}{|c|c|c|c|c|c|c|c|c|c|}
\hline & \multicolumn{3}{|c|}{ VAS-scale } & \multicolumn{3}{|c|}{ Vitality } & \multicolumn{3}{|c|}{ Burnout } \\
\hline & $B$ & $\beta$ & $p$ & $B$ & $\beta$ & $p$ & $B$ & $\beta$ & $p$ \\
\hline \multicolumn{10}{|l|}{ DCS Model $^{1}$} \\
\hline Demands & -0.844 & -0.117 & .006 & -1.833 & -0.195 & $<.001$ & 2.478 & 0.295 & $<.001$ \\
\hline Control & 0.931 & 0.117 & .005 & 1.230 & 0.119 & .006 & -1.054 & -0.114 & .006 \\
\hline Social support & 1.204 & 0.197 & $<.001$ & 1.331 & 0.169 & $<.001$ & -1.287 & -.0184 & $<.001$ \\
\hline$R^{2}$ & & 0.099 & $<.001$ & & 0.162 & $<.001$ & & 0.222 & $<.001$ \\
\hline \multicolumn{10}{|l|}{ ERI Model $^{2}$} \\
\hline Effort & -0.425 & -0.097 & .040 & -1.090 & -0.195 & $<.001$ & 1.298 & 0.263 & $<.001$ \\
\hline Reward & 0.516 & 0.218 & $<.001$ & 0.598 & 0.195 & $<.001$ & -0.724 & -0.267 & $<.001$ \\
\hline$R^{2}$ & & 0.079 & $<.001$ & & 0.141 & $<.001$ & & 0.219 & $<.001$ \\
\hline \multicolumn{10}{|l|}{ JCI Model $^{3}$} \\
\hline Variety & 5.532 & 0.204 & $<.001$ & 6.695 & 0.188 & $<.001$ & -5.988 & 0.189 & $<.001$ \\
\hline \multicolumn{10}{|l|}{ Autonomy } \\
\hline Feedback & 2.107 & 0.088 & .033 & 4.856 & 0.156 & $<.001$ & -5.581 & -0.207 & $<.001$ \\
\hline \multicolumn{10}{|l|}{ Task identity } \\
\hline$R^{2}$ & & 0.060 & $<.001$ & & 0.114 & $<.001$ & & 0.129 & $<.001$ \\
\hline
\end{tabular}

${ }^{1}$ Demand Control Support model

${ }^{2}$ Effort Reward Imbalance model

${ }^{3}$ Job Characteristic Inventory 
Table 4. Simple linear regression of self-rated health and burnout executed on work condition variables at the follow-up $\left(R^{2}\right.$, standardized beta coefficient and $p$-value $)$, controlled for sex, age and education.

\begin{tabular}{|c|c|c|c|c|c|c|c|c|c|c|c|}
\hline \multicolumn{4}{|l|}{ VAS-scale } & \multicolumn{4}{|l|}{ Vitality } & \multicolumn{4}{|l|}{ Burnout } \\
\hline & $R^{2}$ & $\beta$ & $p$ & & $R^{2}$ & $\beta$ & $p$ & & $R^{2}$ & $\beta$ & $p$ \\
\hline Reward & 0.074 & 0.263 & .000 & Demands & 0.110 & -0.245 & .000 & Demands & 0.166 & 0.356 & .000 \\
\hline Variety & 0.052 & 0.217 & .000 & Effort & 0.109 & -0.251 & .000 & Reward & 0.161 & -0.368 & .000 \\
\hline Social support & 0.052 & 0.208 & .000 & Reward & 0.108 & 0.268 & .000 & Effort & 0.160 & 0.353 & .000 \\
\hline Control & 0.036 & 0.177 & .000 & Variety & 0.090 & 0.217 & .000 & Social support & 0.101 & -0.247 & .000 \\
\hline Demands & 0.036 & -0.170 & .000 & Social support & 0.089 & 0.203 & .000 & Feedback & 0.095 & -0.235 & .000 \\
\hline Effort & 0.034 & -0.163 & .000 & Feedback & 0.083 & 0.189 & .000 & Variety & 0.088 & -0.227 & .000 \\
\hline Feedback & 0.022 & 0.125 & .003 & Control & 0.076 & 0.173 & .000 & Control & 0.069 & -0.174 & .000 \\
\hline Task identity & 0.022 & 0.123 & .003 & Task identity & 0.070 & 0.140 & .001 & Autonomy & 0.063 & -0.154 & .000 \\
\hline Autonomy & 0.020 & 0.116 & .005 & Autonomy & 0.064 & 0.136 & .002 & Task identity & 0.054 & -0.112 & .010 \\
\hline
\end{tabular}


Table 5. Multiple stepwise regression analysis on the work conditions with high explained variance $\left(R^{2}\right.$, unstandardized beta coefficient, standardized beta coefficient and $p$-value), controlled for sex, age and education.

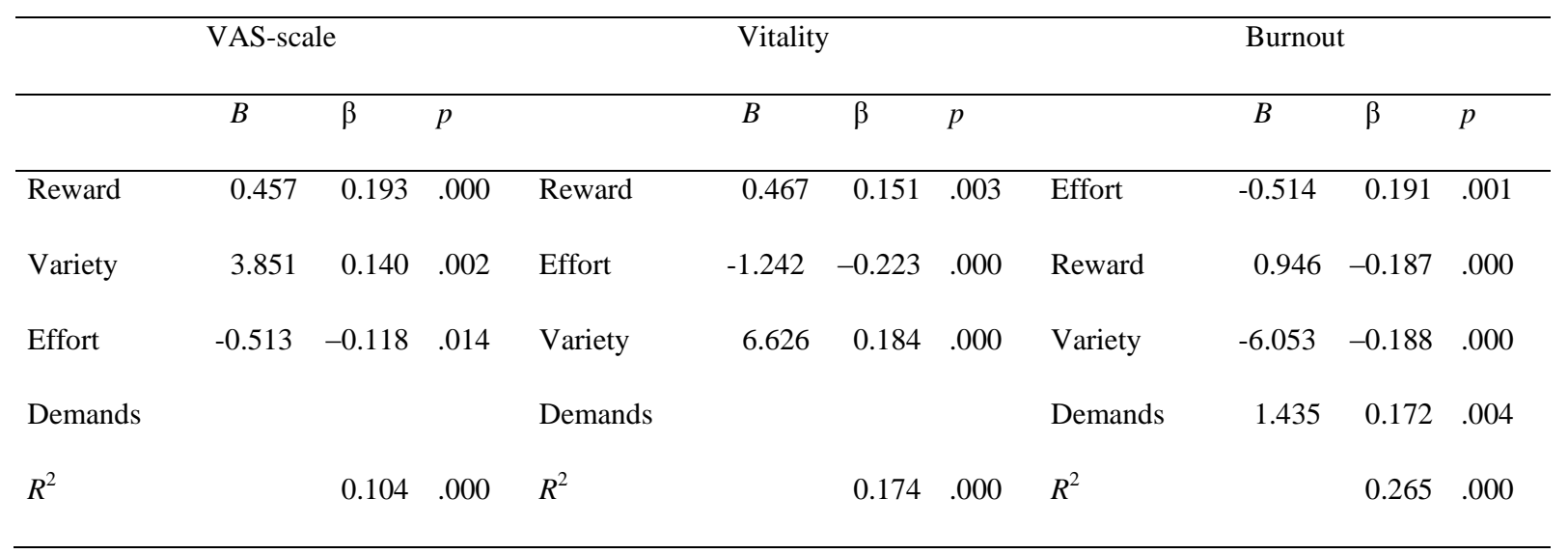

